\title{
Mathematical-task knowledge for teaching
}

\author{
Olive Chapman
}

Published online: 11 January 2013

(C) Springer Science+Business Media Dordrecht 2013

The articles of this issue of the Journal of Mathematics Teacher Education [JMTE] prompted me to think about mathematical tasks and teachers' knowledge of them. Mathematical tasks are central to the learning of mathematics. For example, they can "provide the stimulus for students to think about particular concepts and procedures, their connections with other mathematical ideas, and their applications to real-world contexts" (National Council of Teachers of Mathematics [NCTM] 1991, p. 24). However, they have no life of their own as a tool for learning. It is the teacher and students who give them life based on how they are interpreted and enacted in the classroom. The teacher is critical in shaping the lived task and directing students' activities so that students have opportunities to engage meaningfully in mathematics through them. A teacher could turn an open-ended task into a closed one or a closed one into an open one. He or she could treat a task of high cognitive demand as a low level one or vice versa. There are several factors that could influence this; for example, the teacher's knowledge of content, knowledge of learners, goal for task, instructional orientation, and beliefs about mathematics. In particular, the nature of the teachers' mathematical-task knowledge for teaching is likely to be the determining factor in their treatment of tasks.

Mathematical-task knowledge for teaching deals with the knowledge teachers need in order to (a) select and develop tasks to promote students' conceptual understanding of mathematics, support their development of mathematical thinking, and capture their interest and curiosity and (b) optimize the learning potential of such tasks. This knowledge includes as follows:

1. Understanding the nature of worthwhile tasks - for example, involve significant mathematical content; can be solved in multiple ways; use multiple representations; connect to other important mathematical ideas; require students to justify, interpret, conjecture; have high cognitive demand (e.g., NCTM 1991, 2010; Stein et al. 2000).

2. Ability to identify, select, and create tasks that are rich mathematically in terms of content, pedagogically in terms of affording the learning of mathematics meaningfully

O. Chapman $(\bowtie)$

Faculty of Education, University of Calgary, 2500 University Drive NW,

Calgary, AB T2N1N4, Canada

e-mail: chapman@ucalgary.ca 
and with deep understanding, and personally for students in terms of their interest and learning needs.

3. Knowledge of levels of cognitive demands of tasks (e.g., Stein et al. 2000) and the relationship to goals for the task in terms of the level of learning and understanding of mathematics they can promote.

4. Knowledge of students' understandings, interests, and experiences and the range of ways that diverse students learn mathematics (NCTM1991, p. 25).

5. Understanding of how the tasks teachers select and how they use them influence how students come to make sense of mathematics and of doing and applying mathematics.

6. Knowledge of

what aspects of a task to highlight, how to organize and orchestrate the work of the students, what questions to ask to challenge those with varied levels of expertise, and how to support students without taking over the process of thinking for them and thus eliminating the challenge. (NCTM 2000, p. 19).

Mathematical-task knowledge for teaching, then, is multi-dimensional and thus likely to be challenging for a teacher to construct without meaningful intervention to build on her or his initial sense-making of tasks. In my experience of working with high school mathematics teachers, I have encountered a range of approaches to task selection. For example, there were teachers who assigned the even (or odd) number problems because there were answers to them at the back of the textbook. There were those who intentionally omitted tasks that required non-algorithmic thinking. There were those who minimized the use of word problems or maximized the use of those with contexts that matched students' interests. There were those who considered exploratory tasks at high school level to be a waste of time and have little or no impact on students' achievement in mathematics. Embodied in these actions or thinking are beliefs about tasks that create barriers to students' learning of mathematics and teachers' learning of worthwhile tasks. Such beliefs add to the challenge in helping teachers to develop meaningful mathematical-task knowledge for teaching. An example of this is reflected in the study of Carson (2010), a masters' thesis I supervised.

Carson investigated high school mathematics teachers' (grades 9-12) beliefs about exploratory mathematical tasks in the learning and teaching of high school mathematics. The five teachers who volunteered for the study were participants of a one-day, Exploratory Learning Activity [ELA] workshop that was sponsored by their school system and opened to any of its high school mathematics teacher. They did not use exploratory tasks in their teaching but were interested in learning about them given soon to be implemented emphasis on inquiry in the curriculum. Carson led the workshop in her role as mathematics consultant in the school system. The seven ELAs used in the workshop provided different examples of exploratory tasks, were directly applicable to topics in the curriculum, and could be adapted to the various grades. They involved: number pattern proofs; exploration of patterns in Pascal's triangle; exploration of inverse functions; exploration of properties of polynomial functions; use of mental imagery and spatial memory to recognize and reproduce geometric shapes; exploration of mathematics in female mathematician history stories; and addition and multiplication of radicals through a visual representation. The teachers worked in groups on the task. At the end of each task, each teacher filled out a reflection sheet with prompts that included: What is the mathematics? What do we want students to notice? What is the teacher role? This was followed by whole-class sharing and discussion. 
One aspect of the findings focused on the five participants' thinking about ELAs following the workshop. These teachers' interpretation of ELAs was related to how they viewed students' involvement with them and what they allowed students to accomplish in their learning. Based on their espoused beliefs about ELAs during individual post-workshop interviews, four related themes were identified regarding the beliefs they held about ELAs: ELAs are student centered (e.g., allow students to learn mathematics through discovery instead of being told the concepts, are student directed, and allow for collaborative work). ELAs can increase students' understanding of mathematics. ELAs can enhance students' engagement in learning mathematics (e.g., by increasing interest and enjoyment). ELAs can provide hands-on and/or investigative types of experiences for students.

In spite of these ways of viewing ELAs, the teachers did not modify their views about ELAs in their practice. They viewed them as isolated events in their practice. Carson explained "The teachers' reflection showed that the current and intended use of the ELAs was to occur in pockets of their practice. They did not seem to transfer their beliefs about ELAs into 'how' that can become the dominant pedagogy" (p. 149). Although the tasks used in the workshop were not huge projects, the teachers still viewed ELAs as "elaborate packages" that involve a lot of time to design and require more planning time than is available within their work parameters and environments. As one teacher explained, "You have to actually be willing to give up a lot of your time outside of school, because you are not going to get it done in school" (p.150). They also pointed out that there was no one resource available that provides all of the ELAs applicable to the curriculum, justifying the need for them to create or find them. Carson concluded, "there exists this restrictive beliefs inhibiting the teachers from incorporating ELAs into every day practice" (p. 149). "They do not have the deep understanding of the nature of ELAs to allow an easy transformation of practices" (p. 150). So while the one-day workshop allowed the teachers to make some sense of ELAs as meaningful pedagogical tools, it is not surprising that it was not sufficient for them to develop meaningful task knowledge for teaching in a general way and to confront beliefs they held that justified limiting or avoiding the use of ELAs in their teaching. In fact, the workshop could have unintentionally reinforced their "central beliefs" (Green 1971) that restrict the scope of tasks and how they engage students in them in their classrooms. Thus, in addition to other limitations to this form of intervention, explicit attendance to beliefs should be an important consideration in helping the teachers to transform their thinking about and teaching through ELAs.

In general, engaging teachers in worthwhile tasks may not be sufficient for their development of mathematical-task knowledge for teaching as defined earlier. Such engagement may help them to understand an isolated aspect of this knowledge, but not all of the components that are necessary for meaningful implementation. What an appropriate intervention that takes beliefs into consideration might look like requires ongoing research with explicit focus on mathematical-task knowledge for teaching. However, tasks do play a key role in mathematics teacher education as evidenced in studies in this area. They provide meaningful intervention to enhance teachers' knowledge and practice. The articles in this issue of JMTE further highlight this importance of tasks in teacher learning.

Melissa Brown's article explicitly deals with aspects of mathematical-task knowledge for teaching by focusing on teachers' understanding of selection and implementation of cognitively challenging mathematical tasks. As she explains, improving students' opportunities to learn mathematics with understanding requires mathematics teachers to select and implement high-level tasks in ways that maintain students' engagement in thinking and reasoning throughout an instructional episode. Raisa Guberman and Roza Leikin's article indirectly deals with aspects of mathematical-task knowledge for teaching by engaging 
prospective teachers in solving multiple-solution tasks. While their focus is on developing problem-solving competencies, the experience with these tasks would have likely made the prospective teachers aware of the nature and meaningfulness of such tasks in their teaching. However, the aspect of the work that engaged the prospective teachers in evaluating the level of interest and level of difficulty of the mathematical tasks is more directly related to task knowledge for teaching. The Tonya Gau Bartell, Corey Webel, Brian Bowen, and Nancy Dyson's article deals with prospective teachers learning to tell the difference between evidence of conceptual understanding and procedural knowledge and between features that provide evidence of conceptual understanding and those that do not. While this is not explicitly about tasks, the evidence is based on students' solutions of tasks. The nature of such tasks and their relationship to conceptual and procedural knowledge have implications for task knowledge for teaching. In general, the three articles offer meaningful examples of different interventions to facilitate teachers' learning of tasks and other ways to make sense of teaching mathematics for deep understanding.

Melissa Boston explored an intervention for improving mathematics teaching toward the ideals of NCTM. The Enhancing Secondary Mathematics Teacher Preparation (ESP) Project provided secondary mathematics teachers with professional learning experiences focused on the selection and implementation of cognitively challenging mathematical tasks. A central sequence of activities in the workshop was to engage teachers in solving a cognitively challenging mathematical task, analyze the cognitive demands of the task, and reflect upon instructional artifacts (i.e., students' work) or an instructional episode (i.e., narrative or video cases) of a teacher using the task in a mathematics lesson. Boston explored the connection between the teachers' experiences in the ESP Project, changes in teachers' knowledge, and the observed changes in teachers' instructional practices. Specifically, she addressed the ways in which the teachers' knowledge of the cognitive demands of mathematical tasks changed following their participation in the ESP professional development workshop and the relationship between changes in teachers' knowledge of the cognitive demands of mathematical tasks and their learning experiences in the ESP professional development workshop.

Findings of the study indicated that, at the end of the workshop, the ESP teachers significantly increased their knowledge of the cognitive demands of mathematical tasks and had significantly higher knowledge than teachers in the contrast group. The ESP teachers developed new ideas about the influence of mathematical tasks on students' learning. There was evidence that they became more aware of how high-level tasks support students' learning. However, they often overlooked the underlying mathematical concepts or connections embedded in high-level tasks. In procedures with connections tasks, half of the ESP teachers persisted in identifying the presence of a procedure as the feature that determined the level of cognitive demand ("procedures = low-level"). A small set of teachers focused on features of the task that appeared to be "missing," such as a real-world context or a prompt for an explanation, and appeared to consider both as necessary conditions for high-level demands. However, the teachers no longer rated the level of demand based on the perceived difficulty of the mathematical content or skills. There were changes in their orientations toward their curricula (reform or traditional) in ways that supported the selection of high-level instructional tasks in their own classrooms. In general, the study provides an example of how an intervention involving understanding levels of cognitive demands of tasks can help teachers to improve their knowledge and instructional practices along dimensions of teaching that have been linked to increases in students' opportunities for learning. It also provides insights on a promising approach to help teachers to develop mathematical-task knowledge for teaching. 
Raisa Guberman and Roza Leikin explored the development of teachers' problemsolving competencies through the use of multiple-solution tasks and changes in their views concerning the levels of interest and difficulty of the tasks in a problem-solving course for prospective elementary school mathematics teachers. The authors consider multiplesolution tasks as tasks that contain an explicit requirement for solving a problem in multiple ways. The differences and similarities between the solutions can be illustrated by using: (a) different representations of a mathematical concept, (b) different properties (definitions or theorems) of mathematical concepts from a particular mathematical topic, or (c) different mathematical tools and theorems from different branches of mathematics.

Data analysis included identifying the participants' strategies used in solving the multiple-solution elementary mathematics problems and their ability to produce multiple solutions to the problems and determining their scorings of the level of interest and level of difficulty of the problems they solved. A key finding of the study indicated that the multiple-solution tasks were effective in helping both the participants who were high achievers in mathematics and those who were low achievers to significantly improve their problem-solving competencies. However, the high achievers improved their achievements more pronouncedly than the low achievers. Another key finding was a significant shift in the participants' problem-solving strategies for multiple-solution tasks from mainly trial and error strategies used in the pre-test toward systematic strategies in the post-test. By the end of the course, the participants were solving problems flexibly, changing representations used, and employing more advanced problem-solving strategies.

Finally, regarding the participants' views of the level of interest and difficulty of the tasks, the findings demonstrated that they changed non-significantly in both the systematic (through whole-group discussion with peers) and craft modes (through interviewing school students). The systematic and craft experiences had an opposite influence (in most cases) on the participants' views of interest and difficulty of the problems. For example, after the discussion, the high achieving participants scored the difficulty of the problems lower than before the discussion, yet they increased their scores after the interviews. The correlation between participants' evaluation of problem difficulty and problem interest was found to be significant after solving the problems in pre-test and even more significant after interviewing school students. In general, the study provides an example of how an intervention involving multiple-solution tasks can help prospective teachers to improve their knowledge of problem solving. It also provides insights on the relationship between their evaluation of level of difficulty and level of interest of the tasks that have implication for helping teachers to develop mathematical-task knowledge for teaching.

Tonya Gau Bartell, Corey Webel, Brian Bowen, and Nancy Dyson examined the role content knowledge played in prospective teachers' ability to recognize evidence of children's conceptual understanding of mathematics and the effects of an intervention aimed at supporting them in recognizing evidence of children's conceptual understanding of mathematics. The intervention was designed to include examples in which children used correct procedures and in which they included irrelevant evidence that could be mistaken for evidence of understanding. This was part of a course that focused on developing prospective teachers' mathematical understanding of key number and operation topics typically developed with early grades children. The findings focused on three content areas: comparison and multiplication of fractions and subtraction of decimals. Analysis of the participants' knowledge of these concepts showed that all of the participants demonstrated some evidence of conceptual understanding of subtraction of decimals, most demonstrated some evidence of conceptual understanding of comparison of fractions, but few demonstrated evidence of conceptual understanding of multiplication of fractions. 
Regardless of content knowledge, before the intervention in all three content areas, most participants recognized children's responses demonstrating conceptual understanding as such and most characterized children's procedural responses as evidence of conceptual understanding. Also, content knowledge seemed to support the participants' analyses of responses with conceptual features for comparison of fractions content only. For the comparison of fractions, content knowledge did support participants' in recognizing evidence of children's conceptual understanding but did not for the multiplication of fractions.

The intervention was successful in moving participants away from evaluating responses with conceptual features and procedural solutions as evidence of conceptual understanding for subtraction of decimals content. While some participants also moved away from evaluating such responses as evidence of conceptual understanding for multiplication of fractions content, many still saw these responses as evidence of conceptual understanding after the intervention. This was also true for analyses of procedural responses in the comparison of fractions content. Further, in the areas where there was growth in participants' analyses of children's mathematical work, participants also tended to become critical of children's responses, suggesting that responses with conceptual features or procedural solutions were evidence that the child did not understand the mathematics. The authors concluded that content knowledge is necessary but insufficient in supporting prospective teachers' ability to recognize evidence of children's conceptual understanding of mathematics. While the intervention did prove significant, the fact that even after the intervention many participants considered procedural responses or those containing conceptual features as evidence of conceptual understanding shows room for further growth.

These three articles provide insights into meaningful interventions and possible challenges for helping teachers to enhance their knowledge for teaching mathematics. They have implications for teacher education in relation to mathematical-task knowledge for teaching. For example, collectively, they show the importance of engaging teachers in more that solving worthwhile tasks. They suggest that teachers could also analyze the cognitive demands of the task, reflect upon instructional artefacts (i.e., students' work) or an instructional episode (i.e., narrative or video cases) of a teacher using the task in a mathematics lesson, analyze the problems in terms of level of interest and difficulty, engage in whole-group discussion of multiple solutions with peers, interview school students about tasks, and recognize evidence of children's conceptual understanding in their solutions of tasks. However, ongoing research is necessary to determine the nature of mathematical-task knowledge for teaching in relation to practice and other effective ways to help teachers to develop it.

\section{References}

Carson, R. (2010). High school mathematics teacher' thinking regarding exploratory learning activities. Unpublished Masters Thesis, University of Calgary.

Green, T. (1971). The activities of teaching. New York: McGraw-Hill.

http://www.nctm.org/uploadedFiles/Research_News_and_Advocacy/Research/Clips_and_Briefs/Research_ brief_14_-_Problem_Solving.pdf. Downloaded December 30, 2012.

National Council of Teachers of Mathematics. (1991). Professional standards for teaching mathematics. Reston, VA: National Council of Teachers of Mathematics.

National Council of Teachers of Mathematics. (2000). Principles and standards for school mathematics. Reston, VA: National Council of Teachers of Mathematics.

National Council of Teachers of Mathematics (April, 2010). Research brief: Problem solving.

Stein, M. K., Smith, M. S., Henningsen, M., \& Silver, E. A. (2000). Implementing standards-based mathematics instruction: A casebook for professional development. New York: Teachers College Press. 